\section{Divisions in botany}

\section{Deborah Charlesworth}

Mutation, Developmental Selection, and Plant Evolution. By Edward J. Klekowski, Jr. Columbia University Press: 1988. Pp.373. \$55.

EDWARD Klekowski has made a brave attempt to put together all the available information about mutation in higher plants. His aim is to use the data to support the argument that genetic loads in plants are increased, in comparison to those in animals, by somatic mutation.

The germ cells of higher plants are differentiated anew each reproductive season from several separate meristems, rather than being sequestered in a permanent germ line as in multicellular animals. This means that the number of mitotic cell divisions between the zygote stage and meiosis in the germ cells, which in a plant are formed by a line of cell descent, may on average be much higher than in, say, Drosophila or a female mammal (although the number is, of course, higher in male mammals). If there is some probability of a somatic mutation arising at each cell division, the frequency of mutations among the gametes produced by a tree increases with the number of mitoses, which in plants is correlated with age.

Evidence for a correlation between the number of cell divisions before meiosis and rate of mutation has recently been provided by Miyata's analysis of the rates of evolution of sex-linked loci in mammals, which have many more divisions in the male germ line than in the female (Cold Spr. Harb. Symp. Quant. Biol. LII, $863-867 ; 1987)$. Thus the mutation rate per generation should be higher in a longlived plant, such as a tree, than in shorterlived species. An old tree, or an old clone of a fern species, would also be expected to be chimaeric, with different meristems of the same genetic individual carrying different and independently generated mutations. In the book, a mass of anatomical and developmental detail on meristems illustrates the various patterns that might occur.

Klekowski devotes most of his text to evidence for these ideas. Unfortunately, it is difficult to estimate mutation rates and to compare species with different life spans, and the few data on mutation in plants are mostly from short-lived species. Because a species with characteristics that tend to increase the mutation rate would probably experience selection to reduce it, such estimates might in any case not show the expected differences. Klekowski therefore discusses mutational processes and error correction mechanisms in great detail, but as so little is known about these in plants it is difficult to make the necessary comparisons. The frequency of mutant gametes in plants of different age, and the existence of chimaeras, could also be tested, but here again the data are too limited to be of much use.

In the absence of direct tests of the hypothesis, Klekowski marshalls many pieces of circumstantial evidence that agree with his expectations. This necessarily yields a somewhat confusing picture, as such arguments can be wrong in at least two ways. First, some of the phenomena may not be due to genetic load; for example, although genetic load could be the cause of low numbers of seeds per

\section{Vorsprung durch biotechnologie}

\section{Stephen Oliver}

Biotechnology Focus 1: Fundamentals, Applications, Information. Edited by R.K. Finn and P. Präve. Hanser, Munich/Oxford University Press, New York: 1988. Pp. 436. DM128, \$85.

Rigihtly or wrongly, English has become the international language of science. This is not to say that there is no need for scientific works to be written in other languages, but it does mean that translations into English must be viewed critically.

The American editor of Biotechnology Focus justifies the book's translation from German by asserting that in Europe, unlike the United States, genetic engineering has not excluded microbiology and chemical engineering from the area of biotechnology. I am sure there are those at, say, Madison or the Massachusetts Institute of Technology who would take issue with him. The other contention is that the book will unlock a literature unavailable to English-reading scientists. In fact, the principal biotechnologists in the Germanspeaking world habitually publish in English and less than 12 per cent of the references in Biotechnology Focus are to works in German. The longest chapter is on fungal pathogenicity, which is not an obviously biotechnological subject. This chapter is also one of those with the most German-language works in its bibliography; but it does not provide a ready entry to the German literature because only one of the 61 works (in all languages) quoted is actually referred to in the text. Clearly, editorial rigour has failed on one side of the Atlantic or the other, perhaps a case of passing the buck or Verantwortung abschieben.

Biotechnology Focus is described as a yearbook, but it is not in the mould of the ovule in trees, other explanations such as selection for high pollen production in these plants, are also possible. Second, interpretations other than Klekowski's could explain differences between the genetic loads of populations. Differences in breeding systems, for example, are largely ignored in the book.

Klekowski therefore does not make a watertight argument for his hypothesis. But, although his book is hard to read because of the diversity of the information presented (a glossary would have helped), it is certainly interesting and rich in ideas for future research.

Deborah Charlesworth is in the Department of Ecology and Evolution. University of Chicago, Chicago, IIIinois 60637, USA.

American Society of Microbiology's prestigious "Microbiology" series. Most of the contributions are of broad scope. such as the excellent chapter on scale-up theory by Hempel. This, however, sometimes makes them rather too general, as is the case with the contribution on computer control of antibiotic production. Sometimes a very general title disguises a very specific article — "Fundamental Methods of Genetics" mainly deals with the details of protoplast fusion technology using the hydrocarbon-metabolizing yeast, Yarrowia lipolytica. A great deal of experimental detail can be found in the book, for example in the account of cell immobilization. But this chapter appears in a section labelled "Applied Biotechnology", and so it is curious that the protocols described are for bench-scale work only. Overall, one has the impression that the editors did not have a clear idea of the book's purpose and so the authors have struggled manfully with an inadequate brief.

The topicality that might be expected of a yearbook is provided by an "Information" section. This is a good idea which is spoilt by the time-lag involved in translation - a company profile has Biogen still operating in Geneva, and the market values of bulk bioproducts are given in 1982 deutschmarks. The German-speaking world has made, and is making, an outstanding contribution to biotechnology; it is sad to see it so poorly represented.

Stephen Oliver is a Professor in the Depart ment of Biochemistry and Applied Molecular Biology, and Director of the Manchester Biotechnology Centre, UMIST, PO BOX 88, Manchester M60 1QD, UK.

- Two books published late last year will bo useful to researchers in biotechnology who have an cyc on the potential commercial value of their work. Protecting Biotechnology Inventions: A Guide for Scientists is by Roman Saliwanchik and is published by Science Tech Publishers, Madison. Wisconsin (distributed outside North America by Springer-Verlag): Patents: A Basic Guide to Patenting in Biotechnology is by R. S. Crespi and is published by Cambridge University Press. 